\title{
Os manuais de medicina e a circulação do saber no século XIX no Brasil: mediação entre o saber acadêmico e o saber popular
}

\section{Medical handbooks and the circulation of knowledge in the 19th century in Brazil: mediation between academic knowledge and popular knowledge}

\author{
Betânia Gonçalves Figueiredo**
}

\begin{abstract}
RESUMO
Análise do papel desempenhado pelos manuais de medicina na difusão do saber médico entre a população leiga no Brasil ao longo do século XIX. Os manuais analisados serão escolhidos entre os textos voltados ao público sem formação acadêmica e com dificuldades, de diversas ordens, em encontrar os médicos no século XIX no Brasil. A idéia que norteia o artigo é avaliar em que medida os manuais de medicina popular exerciam o papel de divulgadores do conhecimento médico sistematizado nas academias.

Palavras-chave: educação, medicina, história da ciência, mediação cultural.
\end{abstract}

\footnotetext{
ABSTRACT

This work is an analysis of the role played by medical handbooks for the dissemination of medical knowledge within the lay population in Brazil

* Este artigo está inserido no projeto de pesquisa intitulado "Entre o saber acadêmico e o saber popular: os manuais de medicina popular nos séculos XVIII e XIX", com financiamento do CNPq. Grupo de pesquisa Scientia \& Technica (www.fafich.ufmg.br/ scientia).

** Doutora em Sociologia (USP). Professora do Departamento de História da Universidade Federal de Minas Gerais - UFMG. E-mail: betaniafigueiredo@ig.com.br
} 
throughout the 19th century. The handbooks analyzed will be chosen from the texts directed to the public who did not have academic formation and with difficulties, of different orders, in finding doctors in the 19th century in Brazil. The idea that guides this article is to evaluate to what extent popular medical handbooks played the role of spreading the medical knowledge systematized in the universities.

Key-words: education, medicine, science history, cultural mediation.

"De médico e louco cada um tem um pouco"

É difícil precisar quando este ditado popular começou a circular entre nós. Nos textos de Molière, especialmente no "Doente Imaginário", ${ }^{1}$ a idéia do médico e do hipocondríaco/paciente, revezando nas atividades da arte da cura e da maluquice são duas faces da mesma moeda. Ao longo de toda a peça, escrita no século XVII, perpassa a idéia de que todo aquele autorizado a curar tem lá as suas maluquices e o pobre coitado do paciente, de tanto esperar pela desejada melhora acaba habituando-se às práticas da cura, exercendo, vez por outra, o ofício de curar. O próprio Moliére criticava os médicos e boticários do seu tempo e a monótona variação, resultante da leitura dos ensinamentos hipocráticos pelos homens do período moderno, de aplicar vomitórios e realizar sangrias para qualquer mal físico. Neste ínterim há um tema que merece ser melhor investigado: como são transmitidos os conhecimentos e a prática necessária para exercer a arte de curar. Não só entre os autorizados como também entre os candidatos a exercer o ofício de curar ou a profissão de médico, mas especialmente a transmissão de conhecimentos da área entre o público leigo.

A idéia é de que todos nós, em todos os tempos, em maior ou menor medida, desenvolvemos formas de entendimento do nosso corpo e do corpo do outro. Estamos referindo-nos aos temas da saúde: o que é ser saudável e o seu oposto, a doença, a não-saúde. Cada época constrói seu entendimento das doenças (LE GOFF, s. d.), formas de compreensão do corpo, define os critérios

1 Há um instigante debate em torno da importância da literatura como fonte histórica. Christopher Hill apresenta considerações interessantes em artigo, resultante da transcrição de palestras realizadas na UFMG, em 1993 e publicadas na Varia História. 
e parâmetros para estabelecer os limites entre o corpo são e o corpo doente. Há uma série de pontos que podem contribuir para esta análise: desenvolvimento da comunidade acadêmica, transmissão do conhecimento sistematizado nesses espaços, a utilização dos manuais formadores e de divulgação, entre outros. Mas interessa-nos, em especial, investigar como a difusão do conhecimento sistematizado nos espaços acadêmicos é transmitida pelos conhecidos manuais de medicina popular. Ou como o conhecimento elaborado nos espaços acadêmicos, devidamente traduzido, é recebido e assimilado pelo público não acadêmico.

Se a discussão se referisse ao século XX, utilizaríamos sem grandes problemas os termos difusão, popularização e divulgação da ciência. Mas tratando-se do século XIX no Brasil esta terminologia deve ser empregada com cuidado, pois é necessário realizar algumas ressalvas e utilizá-la de forma cuidadosa. Os principais motivos da inadequação da terminologia são, em primeiro lugar, os problemas advindos da transposição de termos utilizados em períodos posteriores ao problema tratado em século anterior e, em segundo lugar, o fato de que o termo "divulgação da ciência" supõe um movimento estruturado, envolvendo técnicos governamentais de diversas áreas (educação, tecnologia e cultura), escolas públicas e privadas em diversos níveis, imprensa, sociedades científicas, entre outras associações que desejam, de forma deliberada, divulgar os conhecimentos da ciência para a população em geral como mais um ponto necessário em direção à conquista da cidadania.

Mas no século XIX, no Brasil, o problema apresentava-se de forma significativamente diferente. $\mathrm{O}$ acesso à escola formal era bastante restrito. Para não esquecermos do quadro é só lembrar que somente com a vinda da família real ocorreu a autorização de publicar-se no Brasil. Até então todos os livros que circulavam no País eram impressos no exterior.

Há um aprendizado que não perpassa o ensino formal, transmitido entre gerações, nas conversas com médicos e entendidos, nas consultas às farmácias e boticas. Estas situações, difíceis de serem auferidas, indicam que há uma circulação de saber envolvendo pessoas formadas nas academias com pessoas leigas (com ou sem nenhuma formação acadêmica). Em outras palavras, há uma comunicação entre os detentores do saber acadêmico e o público leigo. É necessário destacar que por leigo estamos entendendo todos aqueles que não tiveram formação médica, ou passaram pelos cursos afins. Neste universo encontramos uma significativa variedade de pessoas, que vai desde aqueles que não passaram por nenhuma formação acadêmica, ou aqueles que tiveram acesso a determinados níveis de formação, - não necessariamente na área da saúde -, como também aqueles que aprenderam exercendo a prática, na trans- 
missão de conhecimentos dos mais velhos e assim por diante. Não se trata de um universo homogêneo, muito pelo contrário, há uma diversidade significativamente extensa envolvendo todos aqueles que não passaram pela formação acadêmica na área da saúde. Quando um paciente ouve o médico dandolhe a explicação para o mal que o aflige ocorre um aprendizado informal; quando um farmacêutico explica a ação de determinado medicamento; quando o farmacêutico e o médico ouvem o relato do paciente e buscam enquadrá-lo em determinado quadro de conhecimento, oferecendo uma explicação, há um aprendizado envolvendo os detentores do saber sistematizado e o público leigo.

Enfocaremos especificamente o século XIX no Brasil e o papel desempenhado pelos manuais de medicina. Os manuais que desejamos investigar não são aqueles destinados à formação dos médicos, ou pelo menos não são escritos para esse fim, mas buscamos investigar os manuais que pretendiam estabelecer um diálogo entre o saber sistematizado na área e o público leigo. Entre estes, chamamos a atenção para os dicionários que se destinavam a atender aqueles que estavam longe dos centros urbanos e em localidades de difícil acesso aos médicos credenciados pelas academias e autoridades. São os chamados manuais e ou guias de medicina popular que circularam no Brasil no século XVIII, mas especialmente no século XIX.

Para podermos discutir a importância destes manuais é necessário introduzir o mundo da arte de cura e seus agentes no século XIX no Brasil.

Hoje em dia ninguém questiona a necessidade de um determinado número de médicos para mil habitantes, de acordo com as definições da Organização Mundial da Saúde. Mas nos séculos XVIII até meados do século XIX a situação é bem diferente. Não havia um padrão considerado ideal e principalmente aceito pela população referente à presença dos médicos acadêmicos. Ao contrário, o hábito de recorrer ao médico nos momentos de desequilíbrio da saúde é bem mais recente. Esta forma de delegar ao outro, preparado em espaços acadêmicos formais, a competência para avaliar o estado de saúde do seu corpo foi forjada, junto à população brasileira, ao longo do século XIX, especialmente a partir da segunda metade.

A ausência de profissionais formados nas academias, em diversas regiões do País, ao longo dos séculos XVIII e XIX, não poderia ser sentida como lacuna por parte da população ou como algo que deveria ser preenchido para o bem geral da comunidade. A população estava habituada a lidar com a inexistência deste profissional. Esta era a regra e essa experiência não era vivenciada necessariamente como falta por parte da população.

Sem dúvida o critério que estabelece o número de médicos adequados à população é uma noção construída historicamente mas, independentemente 
dos critérios utilizados para avaliar esse número, não há dúvida que o acesso aos médicos, ao longo de todo o século XIX no Brasil, era difícil. Além da questão numérica, há que se considerar o costume/hábito de procurar o médico, ou seja, o profissional devidamente capacitado e credenciado para exercer a profissão médica. Este movimento de ir ao médico, buscar o auxílio do profissional qualificado, nos momentos de dor, doença e problemas com a saúde do corpo é bastante conhecido por nós hoje em dia, mas há toda uma elaboração para desenvolver o hábito de procurar o médico nos momentos delicados da saúde do corpo.

Há descrições do médico, percorrendo um raio de $50 \mathrm{~km}$, prestando seus serviços (BILHARINHO, 1980, p. 126), ou dos que atendiam nas distâncias possíveis de serem percorridas a cavalo no dia, ou daqueles que seguiam trechos pré-estabelecidos da estrada de ferro para oferecer seus serviços. Os anúncios em jornais indicavam que vários médicos atuavam de forma itinerante pelo interior de Minas, o que provavelmente se repetia em outras regiões do País. O médico chegava, hospedava-se em hotel conhecido, oferecia pelos jornais os seus serviços e a notícia espalhava-se por toda a cidade. Estamos diante de um modelo de atendimento médico itinerante onde o médico deslocava-se em direção aos seus pacientes. Depois de expor as maravilhas do seu currículo, o Dr. F. de Macedo dizia que estaria na cidade de Três Corações, em Minas Gerais, no Hotel Alcântara, a partir do dia 15 de janeiro de 1909, ${ }^{2}$ prática esta que se prolongou pelo século XX. Ao oferecer seus serviços, os médicos ressaltavam que havia disponibilidade para atender chamados, tanto dentro da cidade como nas regiões circunvizinhas (FIGUEIREDO, 2002). Os anúncios informavam, também, que o atendimento dar-se-ia a qualquer hora do dia ou da noite, como foi o caso do médico operador Ascânio P. Mondar, em 1897, quando comunicava que estaria disponível noite e dia para atender aos chamados e que o atendimento aos pobres seria gratuito. ${ }^{3}$

Em muitos casos o atendimento era dado por aqueles que lidavam com áreas afins, como o boticário/farmacêutico ou os dentistas, seguindo o mesmo modelo itinerante dos médicos. No caso dos boticários, esses dividiam seu tempo entre o atendimento nas lojas (farmácias/boticas) e outra parte do tempo visitando os pacientes. $\mathrm{O}$ mais comum era sem dúvida a prática dos dentistas itinerantes que, de ponto em ponto, buscavam cativar sua clientela. A presença do consultório dentário fixar-se-á, entre outros aspectos, com o

2 O Bandolim, Três Corações, n. 5, 3 de janeiro, 1909.

3 Gazeta de Cataguazes, Cataguazes , n. 125, 1897. 
advento da energia elétrica e dos motores movidos a eletricidade. Como Manoel Cândido da Fonseca, que em 1889 anunciou a sua presença no jornal da cidade de Cataguazes, também em Minas Gerais: "Acha-se nesta cidade e aceita chamadas para todas freguesias, e qualquer ponto da Estrada de Ferro Leopoldina." ${ }^{4}$

Os mecanismos de fiscalização de quem poderia ou não exercer os ofícios relacionados aos cuidados com o corpo debilitado foram pouco eficientes. Não havia um controle rigoroso, apesar de observarmos que o cerco aos não autorizados tende a crescer ao longo do século XIX (PIMENTA, 2003).

Há uma série de mudanças na relação médico-paciente, entre elas a definição de que só o médico devidamente formado nas academias deveria cuidar do corpo doente. As associações médicas, as escolas de medicina, o poder legislativo irão atuar, cada qual a sua maneira, para reforçar esta idéia. Nestes casos, há o movimento de distanciamento entre o conhecimento popular do corpo e da doença e os diversos agentes que intervinham: os curandeiros, raizeiros, práticos da medicina e cirurgia, as parteiras, os boticários. Um bom exemplo encontra-se novamente na literatura, quando Machado de Assis, em uma de suas crônicas nos jornais cariocas, informa a perseguição que determinado curandeiro sofreu por parte da polícia. Vamos ao trecho:

Não há curandeiros. O direito de curar é equivalente ao direito de pensar e de falar. Se eu posso extirpar do espírito de um homem certo erro ou absurdo, moral ou científico, por que não lhe posso limpar o corpo e o sangue das corruções? A eventualidade da morte não impede a liberdade do exercício. Sim, pode suceder que eu mande um doente para a eternidade; mas que é a eternidade senão uma extensão do convento, ao qual posso muito bem conduzir outro enfermo pela cura da alma? Não há curandeiros, há médicos sem medicina, que é outra cousa. (MACHADO DE ASSIS, 1892, p. 186)

O texto acima é datado de fins do século XIX. As considerações de Machado de Assis sobre curandeiros, doença e cura foram motivadas pela notícia de que naquele dia (11 de dezembro de 1892) seria preso "um curandeiro conhecidíssimo, do qual é vítima uma pessoa de posição e popular entre

${ }^{4}$ O Povo, Cataguazes, n. 11, 1889. 
nós" (MACHADO DE ASSIS, 1892, p. 186). O texto revela, entre outros aspectos, que os curandeiros não podiam exercer seu trabalho sem o risco de eventual incômodo policial. A legislação indica que, no decorrer do século XIX, principalmente a partir da segunda metade, havia um controle mais rigoroso para o exercício das atividades relacionadas à saúde.

Estas mudanças na relação médico-paciente estão apoiadas em basicamente dois grandes movimentos. O primeiro com o entendimento da medicina (enquanto arte de curar) como um saber que se processa no nível microscópico, exigindo o olhar detalhado, aprofundado e especializado do profissional. $\mathrm{O}$ segundo movimento, concatenado ao primeiro, ocorre no sentido de desenvolver o olhar do médico como um olhar especializado, sofisticado, erudito, que se constrói independentemente do saber popular e muitas vezes em oposição a esse saber. Estes dois movimentos processaram-se ao longo do século XIX, mais precisamente a partir da segunda metade do século XIX.

A partir destes dois grandes movimentos a prática médica altera-se em direção a uma contínua especialização. O conhecimento médico é cada vez mais identificado como um saber erudito, inserido na comunidade profissional e científica. $O$ espaço de intimidade entre o médico e o paciente diminui, profissionaliza-se cada vez mais, e o contato do paciente com o médico modifica-se, delegando ao profissional o controle do processo de conhecimento do corpo e suas alterações. Há um distanciamento entre o conhecimento popular do corpo, da doença e da saúde, do conhecimento acadêmico mais sistematizado e elaborado, conduzido pelo profissional formado e credenciado nos espaços acadêmicos.

Dentro deste quadro geral podemos perceber algumas variações interessantes a serem investigadas. Ente elas, o papel desempenhado pelos manuais de saúde e medicina que circularam no Brasil ao longo do século XIX, especialmente na segunda metade desse século. Elegeremos os manuais que, de acordo com a nossa análise, desempenhavam o papel de divulgadores do conhecimento médico, estabelecendo uma comunicação entre o saber acadêmico (estruturado e sistematizado) e o conhecimento popular. Esses textos partiam da premissa da dificuldade de acesso da população aos médicos, apresentando como evidências desta dificuldade o número de médicos e a sua relação com a população, a distância entre a população e os centros urbanos. Todos estes argumentos podem ser confirmados. A relação entre médicos e pacientes já foi apresentada anteriormente como delicada e em construção. Em função da carência numérica de médicos formados, a legislação buscava contornar o problema possibilitando que práticos, sem terem a formação aca- 
dêmica, mas com determinados aprendizados práticos, em situações especiais, atuassem como médicos.

Entre os manuais que circularam no Brasil no século XIX podemos citar: o Guia médico das mães de mamília (IMBERT, 1873), o Manual do fazendeiro (IMBERT, 1839), o Dicionário de medicina doméstica e popular (LANGGAARD, 1873) e o Médico e o cirurgião da roça (BONJEAN, 1866) entre os mais conhecidos. Mas iremos destacar os chamados Manuais do doutor Chernoviz, como ficaram conhecidas as suas principais obras: o Dicionário de medicina popular e ciências assessórias (1842) e o Formulário e guia médico (1841). É necessário observar que são raros os trabalhos que percebem movimentos entre a chamada medicina popular e a medicina científica (GUIMARÃES, 2003; FIGUEIREDO, 2001 e 2002) e não apenas dois pólos distintos e antagônicos.

O primeiro, voltado especialmente para os locais em que não havia médicos, uma espécie de medicina doméstica, e o segundo, um livro de apoio aos boticários e farmacêuticos. Apesar dessas distinções, todos consultavam os livros de Chernoviz: práticos, acadêmicos, médicos, farmacêuticos e boticários, quer nas emergências, por curiosidade ou para aprendizado. Essas duas publicações tiveram grande repercussão. As primeiras edições esgotaram-se rapidamente e no fim do século, em 1890, o Dicionário de medicina popular, do doutor Chernoviz, encontrava-se já na sua sexta edição, indicando êxito editorial para a época (FIGUEIREDO, 2001).

Pedro Luiz Napoleão Chernoviz ${ }^{5}$ veio para o Brasil em 1840 e morreu quarenta e um anos depois em Passy, França, 1881. Chegou ao Rio de Janeiro em busca de fama e fortuna. Formara-se em Montpellier, ao que tudo indica, em cirurgia e não em medicina.

De acordo com o Dr. Chernoviz, havia um campo inexplorado localizado em publicações referentes à prática da medicina: "chegando aqui, percebi que este trabalho aplicado no Brasil poderia ser de grande utilidade, porque preencheria a falta que existe do assunto na língua portuguesa." (HERSON, 1996, p. 402). É interessante não esquecer que Chernoviz é europeu e recebeu sua formação na Europa, convivendo com esse tipo de literatura. Analisa a situação brasileira e percebe as possibilidades de investir (financeiramente e intelectualmente) no campo inexplorado (ou pouco explorado) da divulgação do conhecimento acadêmico junto à população não acadêmica. Neste sentido estabelece-se um canal sistemático de comunicação.

\footnotetext{
${ }^{5}$ Chernoviz aportuguesou o seu nome: Piotr Czerniewicz . (HERSON, 1996, p. 388).
} 
Ao que tudo indica, o sucesso das publicações foi imediato. Como observou o próprio Chernoviz "nos três primeiros dias [após a publicação], foram vendidos 300 exemplares que me permitiram não somente cobrir os gastos da impressão, como ainda sobrou algo pelo meu trabalho."(HERSON, 1996, p. 406). O investimento realizado na execução do projeto foi coroado de pleno êxito. As duas obras tiveram boa repercussão e em 1904 o Dicionário de medicina popular já se encontrava na $14^{\mathrm{a}}$ edição, utilizada por fazendeiros, práticos da saúde, médicos e boticários. Em toda a farmácia que se prezasse encontravam-se as publicações do Doutor Chernoviz (FIGUEIREDO, 2001). Há notícias de que a primeira edição, do Dicionário de medicina popular, em 1842 , recebeu uma tiragem de três mil exemplares, número sem dúvida extremamente significativo para a época. Independentemente do número de exemplares por edição, uma informação relevante é o fato de que tanto o Dicionário como o Guia tenham recebido diversas edições ao longo do século. Em cada nova edição das obras havia sempre o destaque de que lhes haviam sido acrescidos os avanços da ciência na área. Há um interesse em manter as obras atualizadas e, ao que tudo indica, essa preocupação gerava impactos positivos nas vendas.

A percepção do complexo emaranhado que lhe possibilitaria atingir sucesso, como bem expressa o nosso médico-autor, não poderia restringir-se a uma contabilidade tão simples que considerasse apenas gastos e ganhos, pois a ambição de fama e fortuna estavam emaranhadas e, conseqüentemente, uma não poderia ser obtida sem a outra. Havia necessidade de atuar em outras frentes, de tornar-se conhecido dentro das esferas sociais bem sucedidas. Ao dedicar a primeira edição do Dicionário de medicina popular ao Imperador, Chernoviz sabia muito bem por onde estava andando, buscava ser conhecido e admirado nas altas rodas sociais. Mais uma vez confirma-se a idéia vigente na área médica, no Brasil do século passado, de que a reputação do médico era construída, principalmente, relacionada ao ambiente social de sua clientela. Esta noção de como decifrar o enigma do sucesso médico no País é que levou o doutor Chernoviz a disputar uma vaga na Academia Médica Real, no Rio de Janeiro e, provavelmente, também levou-o a naturalizar-se brasileiro, mesmo não sendo esta uma exigência para o exercício da profissão no País.

Chamamos a atenção para o primeiro movimento de almejar e obter uma vaga na Academia Médica Real. Este movimente corresponde ao desejo e interesse em dialogar com os pares e, preferencialmente, ser reconhecido por eles. Não se trata de um leigo, e sim de um profissional, com formação acadêmica na área em Universidade européia reconhecida na época, Montpellier. Ou seja, estamos nos referindo às validações da comunidade acadêmica. 
Com relação a essa vaga na Academia Médica Real o nosso doutor dá o seu parecer-diagnóstico, em correspondência datada de 27 de novembro de 1840: "Este título de novo membro da Academia não me trouxe nada mais que um pouco de honra, alegrou-me muito, pois apontou-me ao olhar público" (HERSON, 1996, p. 402). Novamente deixa transparecer um desejo duplo: reconhecimento que possibilitasse fama e, conseqüentemente, fortuna. Talvez esta obstinação em obter fama e fortuna, de uma certa forma desprezando a atuação da própria Academia, tenha levado, anos mais tarde, ao seu pedido de demissão, aceito com satisfação pelo editor dos Annaes de Medicina. De acordo com o editor, a saída de Chernoviz veio em boa hora, pois ele nunca comparecia às reuniões: "Felizmente o sr. Chernoviz teve consciência: julgou de si para si (e julgou muito bem) que lhe era indecoroso ser membro de uma associação, sem concorrer em nada para o seu brilho e engrandecimento, e por isso enviou seu pedido de demissão. Honra lhe seja feita, e agradeçamolhe tão acertada deliberação" (COElho, 1999, p. 72). ${ }^{6}$ Ao que tudo indica, o doutor Chernoviz, além de fama e fortuna, também encontrou desafetos. Mas o importante é ressaltar que houve uma intermediação, no caso sem o sucesso pretendido, por razões que não podemos investigar neste artigo, entre o autor das obras destinadas à divulgação do conhecimento médico e os espaços acadêmicos da época.

A organização do Dicionário de medicina popular é bastante reveladora. $\mathrm{O}$ texto foi organizado nas suas primeiras edições em dois volumes, como nos dicionários, em ordem alfabética, onde o autor deixa todo o depoimento pessoal nos trechos introdutórios. No Dicionário, as doenças estão relacionadas diretamente aos órgãos e aos medicamentos, sempre referências desconectadas do quadro nosológico. Há toda um intercalação entre os verbetes, quando um tema pode ser aprofundado seguindo as indicações de temas afins.

Um dos caminhos para percorrer a construção das redes de comunicação estabelecidas pelos manuais é, na medida do possível, buscar identificar as interlocuções necessárias para elaboração e divulgação dos textos, assim como acompanhar a aceitação, ou não, à circulação deste tipo de publicação. Os autores desses manuais podem ser analisados como desempenhando o papel de intermediários entre o conhecimento acadêmico de suas respectivas épocas e a comunidade, exercendo o papel de mediadores culturais na área da medicina. Em alguns casos já foi possível identificar diálogos da comunidade acadêmica com os autores dos manuais, como o exemplo do doutor Chernoviz

${ }^{6}$ Annaes de Medicina Brasiliense, v. 4, n. 6, dezembro de 1848, p. 128-129. 
enfrentando problemas com a Academia Médica Real, no relato citado anteriormente.

De acordo com Edmundo Campos Coelho, em estudo sobre as profissões imperiais, a competência profissional do médico, no Brasil do século XIX, avaliava-se, principalmente, por um conjunto de fatores como domínio de uma língua estrangeira, conhecimento das teorias médicas mais em voga na Europa, adequada proveniência social, uma certa cultura humanística, apropriadas referências sociais (de outros clientes notáveis), e não necessariamente por aprovação dos pares, da comunidade médica. Em outros termos, a competência profissional era atestada muito mais pela clientela, influenciada pelo prestígio da profissão, do que pela comunidade médica e pela eficácia da intervenção profissional.

A repercussão do Dicionário de medicina popular e do Guia e do Formulário médico deve ser considerada não apenas pelas diversas edições mas, na medida do possível, acompanhando um pouco a trajetória dos seus leitores. Inicialmente cabe identificar e analisar quem lia e como liam esses textos. Em seguida, acompanhar a repercussão das obras do doutor Chernoviz, que não se limitou aos limites da corte no Brasil, mas espalhou-se pelo país com traduções para outros países. E, finalmente, observar o conteúdo de popularização do conhecimento deste tipo de publicação.

Não há dúvida de que as obras do Dr. Chernoviz eram lidas e utilizadas no dia-a-dia. Pode-se constatar que com interesses, opiniões e objetivos distintos, todos os envolvidos com a arte de curar liam esse gênero de textos. Além dos envolvidos com a arte de curar, há uma apropriação dos textos pelo público a que estas publicações se destinavam: os lares urbanos ou rurais, distantes do acesso aos conhecimentos sistematizados, do saber médico. Vamos acompanhar um pouco a recepção desses manuais por diversos caminhos documentais: legislação, literatura, inventários e testamentos.

Na legislação mineira, no século XIX, ao definir os critérios para o bom funcionamento da farmácia, incluíam-se entre os livros imprescindíveis o Formulário e guia médico do doutor Chernoviz. Ao lado de todo vasilhame necessário para ter e manter em funcionamento uma farmácia de acordo com os critérios da lei havia também uma relação de livros necessários para desempenhar as funções de uma farmácia adequadamente. Há notícias de um afamado médico prático ${ }^{7}$ que atuava na região de Curvelo e vizinhaças e an-

7 Médico prático é aquele que exerce a profissão de médico sem ter a formação acadêmica. Ele aprendeu a arte de curar com algum médico credenciado e se submeteu aos exames que o permitem atuar. Esta situação foi comum no século XIX no Brasil. 
dava sempre com o "Chernoviz" debaixo do braço (CRUZ, 1965, p. 33). Diante da dúvida consultava-se um desses guias. As publicações do Chernoviz (Guia e Dicionário) encontravam-se entre as mais populares. Este fato permite-nos concluir que as informações contidas no Guia Prático de Saúde de Chernoviz eram realmente lidas e muitas vezes aplicadas à população doente.

Outros curadores aliavam a habilidade à possibilidade de faturar alguns trocados. Encontramos referências a dois curandeiros na passagem do século, em Curvelo (entre 1875-1910). Um deles era Manoel Martins, conhecido como Mané Martins. Homem branco, que costumava andar com roupas brancas de algodão grosseiro. Era sempre visto com uma capanga de lado que, entre outras coisas, guardava uma edição do Chernoviz:

o Chernoviz era seu fiel conselheiro, seu mestre e seu guia, e quantas vezes o salvou da desmoralização e do fracasso certo, quando, frente a determinados casos difíceis da sua "clínica", se encontrava num verdadeiro beco sem saída, sem atinar com o remédio adequado para o doente em estado grave (CRUZ, 1965, p. 33).

Como o Mané Martins, vários outros curadores espalhavam-se levando um pouco de seus conhecimentos e experiências. Neste caso, as roupas brancas utilizadas pelos médicos foram adaptadas pelo curandeiro do sertão: algodão grosseiro. Os ensinamentos foram obtidos por meio de guias como os do Dr. Chernoviz, acrescentando-se a prática, a sensibilidade. Muitos fazendeiros e chefes de família no interior faziam as vezes de "Mané Martins" pois viam-se obrigados a providenciar soluções para os problemas de saúde das pessoas, desempenhando, muitas vezes, o papel de médicos. Para tanto, contavam com o auxílio dos guias populares de medicina, das boticas portáteis com os medicamentos mais utilizados e com a ajuda dos "entendidos" de medicina na região (FIGUEIREDO, 2002).

Iremos trabalhar a linguagem e estrutura dos textos que auxiliarão a compreender por que esses manuais podem ser adjetivados de populares, no sentido de desenvolverem uma interlocução ou mediação entre o saber popular e o saber produzido nas academias. No desenvolvimento dos verbetes do Dicionário observa-se um esforço deliberado por apresentar uma linguagem de fácil compreensão para os não-habilitados ao mundo da ciência médica. A descrição do coração, por exemplo, é bastante singela e reveladora. Vamos acompanhá-la: 
órgão oco e muscular, que se acha no interior do peito, um pouco do lado esquerdo, agente principal de circulação do sangue, tem a forma de um pão de açúcar ou de uma pirâmide achatada. $\mathrm{O}$ seu volume, um pouco mais considerável no homem do que na mulher, equivale pouco mais ou menos ao da mão fechada de um homem. (...) (CHERNOVIZ, 1878, p. 706)

A descrição continua apresentando as divisões internas e as propriedades de contração e dilatação do coração e informando que "estas noções são indispensáveis para compreender a descrição da circulação do sangue".

Ao acompanharmos a descrição em alguns dos manuais destinados à formação dos médicos, encontramos um universo bastante diferenciado, muito mais elaborado e sofisticado. Vamos utilizar dois manuais de formação. $\mathrm{O}$ primeiro deles refere-se ao Tratado das Moléstias do Coração, de Martins Costas, publicado em 1889, dedicado "a sua magestade o senhor D. Pedro II, Imperador Constitucional e defensor perpetuo do Brasil". A dedicatória foi lembrada devido ao Dicionário de medicina popular do doutor Chernoviz também ter sido dedicado ao Imperador, no caso, Pedro I. Neste tratado encontramos, nas preliminares, a anatomia e fisiologia do coração, desenvolvidas em 48 páginas. $\mathrm{O}$ início da descrição é precedida por uma relação bibliográfica referente ao assunto, demonstrando, no mínimo, a necessidade de erudição para ser introduzido ao assunto. Entre a relação de referências bibliográficas encontramos desde Hipócrates (Tratado do coração) e Vesalius (De humani corporis fabrica) até textos mais atuais. Vamos acompanhar alguns trechos dos parágrafos iniciais:

Órgão músculo-membroso, oco, essencialmente contráctil, centro do aparelho circulatório, o coração está situado um pouco obliquamente na parte anterior da cavidade toráxica (...) Apresenta a forma mais ou menos cônica, tendo a base voltada para cima, para a direita e para trás, atingindo o nível do segundo espaço intercostal (...) (JACCOUD, 1868, p. 3)

Já o Nouveau dictionnaire de médecine et de chirurgie pratiques, do doutor Jaccoud, publicado em $1868,{ }^{8}$ em vários volumes, encontramos o verNava.

${ }^{8}$ Disponível no acervo do Centro de Memória da Medicina - UFMG, na coleção Pedro 
bete coração desenvolvido em 432 páginas, assinadas por Maurice Raynaud, ocupando praticamente a metade do volume 8 do dicionário. Inicia-se com uma pequena descrição do nome coração, seguida por uma explicação anatômica e fisiológica (divididas em estrutura e ações mecânicas), a intervenção no coração, e suas anomalias. $O$ estudo das patologias foi dividido em breve histórico, lições anatômicas, etiologia das doenças do coração, sintomas das doenças, complicações em geral e os tratamentos. Todo este trabalho é intermediado por vasta citação bibliográfica.

Estas duas referências auxiliam-nos a compreender que o conhecimento disponível referente ao coração não se limitava à explicação fornecida pelo Dicionário de medicina popular, ou seja, a explicação do Dicionário é uma simplificação destinada a atingir o público leigo.

Após acompanhar alguns dos leitores e suas leituras dos manuais do doutor Chernoviz, é possível nos encaminharmos para a conclusão. Esses manuais estabeleciam uma circulação do saber produzido e disseminado nas academias junto ao público leigo. Mais do que suprir uma demanda do mercado, estas publicações contribuíram para o movimento de autorização do saber e discursos médicos. Mesmo recebendo a oposição das instituições médicas, como no caso do descredenciamento do doutor Chernoviz da Academia, estes manuais populares cumpriram o papel de mediadores culturais. É importante observar que ao mesmo tempo em que constatamos que a instituição médica em questão acelerou o processo de desligamento do Dr. Chernoviz, em algum momento o seu credenciamento lhe trouxe benefícios. Há uma relação conflituosa entre as estruturas formais de saber médico e a prática de homens como o Dr. Chernoviz e a circulação de seus manuais. Se por um lado os espaços formais de ensino e credenciamento profissional desqualificavam o movimento de popularização do conhecimento médico, a partir da circulação de manuais direcionados ao público leigo, na tentativa de se fortalecer o campo de atuação dos médicos formados nas academias; por outro lado, há uma cultura ainda sendo forjada na área, o que possibilitava que muitos médicos e farmacêuticos utilizassem esses textos, e em certa medida tais textos cumpriam o papel de fornecer algumas informações desejadas. E, finalmente, é necessário observar a relação conflituosa do Dr. Chernoviz com a Academia. Em um primeiro momento ser integrante da Academia trouxe-lhe a expectativa de reconhecimento e credibilidade. Provavelmente as críticas ao seu trabalho não demoraram a surgir, fazendo com que este se desligasse.

Sem dúvida, o campo de investigação dos manuais de divulgação da medicina constitui campo rico e pouco explorado. São vários os caminhos de análise que se apresentam: história cultural da ciência, mediação cultural en- 
tre conhecimento acadêmico e conhecimento popular, difusão do conhecimento médico, os leitores e as formas de leitura dos manuais. O caminho está aberto.

\section{REFERÊNCIAS}

ASSIS, M. de. Obras completas. A semana, v. 5, 11 de dez. de 1892.

BILHARINHO, J. S. História da Medicina em Uberaba. Uberaba: Academia de Letras do Triângulo Mineiro, 1980.

CHERNOVIZ, L. N. Dicionário de Medicina Popular. 5. ed. Paris: Casa do autor, 1878.

COELHO, E. C. As profissões imperiais: medicina, engenharia e advocacia no Rio de Janeiro 1822-1930. Rio de Janeiro: Record, 1999.

CRUZ, G. L. da. Livro verde das plantas medicinais e industriais do Brasil. Belo Horizonte: [s.n.], 1965.

FIGUEIREDO, B. G. A arte de curar: cirurgiões, médicos, boticários e curandeiros no século XIX em Minas Gerais. Rio de Janeiro: Vício de Leitura, 2002. maio 2001 .

Chernoviz e a medicina no Brasil do século XIX. Estudos, v. 1, n. 1, p. 95-109,

GUIMARÃES, M. R. C. Civilizando as artes de curar: Chernoviz e os manuais de medicina popular no império. Rio de Janeiro, Programa de Pós-graduação em História das Ciências da Saúde COC/Fiocruz, 2003.

HERSON, B. Cristãos-novos e seus descendentes na medicina brasileira (1500-1850). São Paulo: Edusp, 1996.

JACCOUD, S. (Org). Nouveau Dictionnaire de Médecine et de Chirurgie Pratiques. Paris: J. B. Baillières et Fils, 1868.

LE GOFF, J. As doenças têm história. Lisboa: Terramar, [s.d.].

PIMENTA, T. S. Terapeutas populares e instituições médicas na primeira metade do século XIX. In: CHALHOUB, S. et al. (Orgs). Artes e oficios de curar no Brasil. Campinas: Unicamp, 2003. p. 307-330.

Texto recebido em 06 nov. 2004 Texto aprovado em 23 jan. 2005 